\title{
PENGEMBANGAN MEDIA BRIGHT BARCODE BOX STORAGE BERBASIS DIGITAL LITERACY ACCELERATION SKILLS IN THE KNOWLEDGE AGE UNTUK MENINGKATKAN KETERAMPILAN BELAJAR ABAD 21 (THE 21st Century Skills Future Students' Competencies)
}

\author{
Feri Tirtoni $^{1)}$, Ika Ratna Indra Astutik ${ }^{2)}$ Fitria Wulandari $^{3)}$ \\ ${ }^{1,2,3}$ Universitas Muhammadiyah Sidoarjo \\ Email:feri.tirtoni@umsida.ac.id ${ }^{1}$,ikaratna@umsida.ac.id ${ }^{2}$,wulandarifitria17@gmail.com ${ }^{3}$
}

\begin{abstract}
Abstrak
Penelitian pengembangan desain media yang inovatif yaitu "(B3-S) Bright Barcode Box Storage Berbasis Digital Literacy Acceleration Skills In The Knowledge Age "Media yang dapat meningkatkan kemampuan skill literasi digital sejalan dengan tuntutan pendidikan di Era Pembelajaran Abad 21 (The 21st Century Skills) pada siswa kelas III SD pada saat proses pembelajaran. Adapun system Penggunaan media yang dikembangkan tersebut bersubstansi pada penguasaan keterampilan belajar Abad 21 dimana akan membekali siswa dengan pengalaman belajar yang kreatif inovatif dan menyenangkan dalam suasanan belajar melalui optimalisasi 4 jenis keterampilan sekaligus yaitu Communication, Collaboration, Critical Thinking and Problem Solving, Creativity and Innovation, dimana dalam penggunaan media (B3-S) Bright Barcode Box Storage siswa diberikan kesempatan menggunakan kemampuannya untuk mengutarakan ide-ide dari siswa pada saat melakukan aktifitas literacy melalui problem solving melalui fitur tools berupa game board advance berteknologi barcode system, serta barcode flash car. Berdasarkan hasil uji coba ke-1 dan uji coba II yang telah dilaksanakan pada penelitian ini ditemukan sebuah data baru bahwa mata pelajaran Tematik K-13 pada kelas III SDN Ketajen Sidoarjo terdapat adanya peningkatan kerampilan belajar siswa yang naik dengan menggunakan media interaktif digital sebesar 76\% dalam hal kemampuan Communication, Collaboration, Critical Thinking and Problem Solving melalui (B3-S) Bright Barcode Box Storage .
\end{abstract}

Kata kunci: Pembelajaran tematik SD kelas III, (B3-S) bright barcode box storage berbasis digital literacy acceleration skills, the $4 c$ skills, the age knowledge, the 21st century skill.

\begin{abstract}
Research into the development of innovative media designs namely "(B3-S) Bright Barcode Box Storage Based on Digital Literacy Acceleration Skills In The Knowledge Age" Media that can enhance the ability of digital literacy skills are in line with the demands of education in the 21st Century Learning Era (The 21st Century Skills) in third grade elementary school students during the learning process. The use of the developed media system has a substance in the mastery of 21 st Century learning skills which will equip students with a creative learning experience that is innovative and fun in a learning environment through the optimization of 4 types of skills at once namely Communication, Collaboration, Critical Thinking and Problem Solving, Creativity and Innovation, where in the use of Bright Barcode Box Storage (B3-S) media students are given the opportunity to use their ability to express ideas from students when carrying out literacy activities
\end{abstract}


through problem solving through the tool features in the form of game board technology with barcode system, and barcode flash car. Based on the results of the first and second trials that have been carried out in this study, a new data was found that the Thematic K-13 subjects in class III SDN Ketajen Sidoarjo there was an increase in students' learning skills that rose using digital interactive media by $76 \%$ in terms of Communication, Collaboration, Critical Thinking and Problem Solving capabilities through (B3-S) Bright Barcode Box Storage.

Keywords: Third grade elementary thematic learning, (B3-S) bright barcode box storage based on digital literacy acceleration skills, the $4 c$ skills, the age knowledge, the 21 st century skill.

\section{PENDAHULUAN}

Pembelajaran Tematik pada K-13 di Sekolah Dasar merupakan pengkaitan dari beberapa mata pelajaran menjadi satu tema. Pengajaran dengan menggunakan pembelajaran terpadu dapat membuka cakrawala guru-guru yang inovatif, produktif, dan demokratis serta dapat mengatasi kepasifan siswa yang kurang semangat dalam kegiatan belajar mengajar di sekolah (Cucu Suhana, 2014 : 97). Guru sebagai ujung tombak pendidikan harus mampu menguasai 4 kompetensi pendidik yaitu kompetensi pedagogik, profesional, kepribadian, dan sosial. Sebagaimana yang dituangkan dalam Undang-Undang Guru dan Dosen nomor 14 tahun $2005 \mathrm{Bab} 1$ pasal 1 ayat 1 yang berbunyi guru adalah pendidik profesional dengan tugas utama mendidik, mengajar, membimbing, mengarahkan, melatih, menilai, dan mengevaluasi peserta didik pada pendidikan anak usia dini jalur pendidikan formal, pendidikan dasar, dan pendidikan menengah.

Pada pembelajaran tematik, siswa dapat memanfaatkan keterampilannya yang dikembangkan dari mempelajari keterkaitan antar mata pelajaran (Atwi Suparman , 2014 : 33). Pembelajaran terpadu membantu siswa dapat memecahkan masalah dan berpikir kritis untuk dapat dikembangkan melalui keterampilan dalam situasi nyata atau praktek. Dalam pembelajaran terpadu, disetiap mata pelajaran mempunyai keterkaitan konsep antara mata pelajaran satu dengan mata pelajaran lainnya, sehingga materi pelajaran menjadi lebih bermakna. Dimana nantinya system Penggunaan media yang dikembangkan pada pembelajaran terpadu tersebut bersubstansi pada penguasaan keterampilan belajar Abad 21 dimana akan membekali siswa dengan pengalaman belajar yang kreatif inovatif dan menyenangkan dalam suasanan belajar melalui optimalisasi 4 jenis keterampilan sekaligus yaitu Communication Collaboration, Critical Thinking and Problem Solving, Creativity and Innovation (Frank Bobbit. 2017:56 ).

Latar belakang dan Urgensi dalam penelitian ini adalah sejalan dengan perkembangan isu-isu pendidikan yang telah memasuki Era Literacy Acceleration In The Knowledge Age yang mewajibkan peserta didik wajib menguasai Keterampilan Belajar Abad 21(The 21st Century Skills). Maka pentingnya peranan inovasi media pembelajaran untuk anak usia SD adalah suatu hal yang mutlak dilakukan sebab media merupakan alat bantu yang digunakan untuk mengenalkan tema- tema sebagai bahan ajaran atau yang sering disebut dengan intergrasi media pembelajaran untuk kurikulum untuk anak usia SD, dimana 
semakin banyak alat indra yang terlibat dalam proses belajar maka semakin besar kemungkinan anak paham pada materi yang disampaikan oleh pengajar atau guru (Suhardan, D. 2009 : 77).

Dilapangan ditemukan kembali sebuah data dari permasalahan pada sisi rendahnya ketrampilan proses belajar siswa di SDN Ketajen 1 Sidoarjo Sidoarjo yaitu sebesar 71 $\%$ siswa di kelas III mengalami kesulitan dalam proses keterampilan 4C Collaboration skill, Communication skill, Critical Thinking and Problem Solving skill, Creativity and Innovation skill saat PBM dari total 26 siswa didalam kelas, data ini berdasarkan hasil observasi peneliti yang dilakukan pada tanggal 28 Oktober 2019. Maka dari Latar belakang permasalahan diatas diperlukan suatu cara untuk meningkatkan ketrampilan Keterampilan Belajar 4C di era Abad 21 siswa SD melalui pengembangan media "(B3-S) Bright Barcode Box Storage Berbasis Digital Literacy Acceleration Skills In The Knowledge Age “.

Penelitian ini bertujuan untuk : (1) Mendeskripsikan proses pengembangan media (B3-S) Bright Barcode Box Storage Berbasis Digital Literacy Acceleration Skills untuk meningkatkan kemampuan "The $4 C$ Skills" siswa SD kelas III pada mata pelajaran Tematik. (2) Mendekripsikan hasil pengembangan pengembangan media $(B 3-S)$ Bright Barcode Box Storage Berbasis Digital Literacy Acceleration Skills untuk meningkatkan keterampilan 4C collaboration skill, communication skill, critical thinking and problem solving skill, creativity and innovation skill pada era literacy acceleration in the knowledge age in the 21st Century Skills.

Hal ini sesuai dengan penelitian (Widya Martika, 2018) yang menyatakan pada saat ini umumnya di sekolah perkotaan maupun perdesaan media pembelajaran yang dominan masih digunakan adalah metode tatap muka dengan media buku paket dan LKS yaitu sebesar 78\% dari sampel 112 sekolah di Jawa Timur, dimana baru sekitar $22 \%$ sekolah kreatif yang telah mengembangkan media pembelajaran berbasis teknologi online digital. Dan hal ini juga dikuatkan oleh penelitian (Heru Wijanarko, 2019) yang menyatakan bahwa siswa SD kelas III pada anak usia 9-10 tahun gampang bosan dan lebih tertarik dengan hal baru yang berisi pengalaman belajar baru "new experience learing" yang mengkolaborasikan antara konten materi pelajaran dengan sistem teknologi pembelajaran berbasis media digital online.

Menurut Teori operasional kongkret oleh Jean Piaget, bagi siswa yang berada pada tahap operasional kongkret 7-12 tahun, belajar sambil bermain memungkinkan mereka menemukan konsep-konsep. Sehingga, siswa SD kelas III berada pada kisaran tahap operasi kongkret, selain membutuhkan media sebagai alat bantu, mereka juga membutuhkan suatu wadah aktivitas berupa permainan dalam pembelajaran (Mulyasa. 2014: 89)

Adapun dasar yang digunakan peneliti untuk melakukan penelitian ini antara lain adalah beberapa hasil data penelitian relevan yang terkait dengan tema yang sama seperti Data : Pada Tahun 2017 Penelitian oleh Feri Tirtoni , dengan Judul "Pengaruh Role Model pembelajaran Saintific Berbantuan Media Kreatif Bright Barcode Box Storage Untuk Meningkatkan Kemampuan collaboration skill", ditemukan sebuah data bahwa ada sebuah pengaruh peningkatan dalam proses Kemampuan collaboration skill sebesar 72,8 $\%$ setelah guru mengajar mapel tematik dengan Model Model pembelajaran Saintific Berbantuan Media Kreatif Bright Barcode Box Storage. (penelitian dilakukan pada siswa kelas 3 di SDN 1 Jemundo), kemudian 
Pada Tahun 2018 Penelitian oleh Feri Tirtoni , dengan Judul "Optimalisasi Media Kreatif Bright Barcode Box Storage Berbasis problem solving skill untuk Meningkatkan Keterampilan critical thinking Pada Kurikulum K-13. ditemukan sebuah data bahwa ada sebuah pengaruh peningkatan dalam Keterampilan Soft Skill siswa sebesar $74,6 \%$ setelah guru mengajar mapel tematik dengan melakukan optimalisasi Media Kreatif Bright Barcode Box Storage Berbasis problem solving skill untuk Meningkatkan Keterampilan critical thinking Pada Kurikulum K-13 (penelitian dilakukan pada siswa kelas 3 di SDN Sedati Gede1).

Dari Road Maap penelitian yang telah dilakukan oleh peneliti sebelumnya yang juga membahas tema permasalahan yang sama inilah yang menjadi sebuah dasar untuk melanjutkan penelitian serupa mengenai Bright Barcode Box Storage ini, yang dapat menjadi salah satu solusi alternative permasalahan pada sisi rendahnya ketrampilan proses belajar siswa di SDN Ketajen 1 Sidoarjo Sidoarjo yaitu sebesar $71,4 \%$ siswa di kelas III mengalami kesulitan dalam proses keterampilan 4C Collaboration skill, Communication skill, Critical Thinking and Problem Solving skill, Creativity and Innovation skill saat PBM dari total 26 siswa didalam kelas, data ini berdasarkan hasil observasi peneliti yang dilakukan pada tanggal 28 Oktober 2019 . Dan salah satu tujuan penggunaan media ini adalah peneliti berharap keberadaan media ini berfungsi untuk meningkatkan keterampilan belajar pada mapel tematik yang berorientasi pada proses keterampilan 4C Abad 21 siswa SD melalui pengembangan media "(B3-S) Bright Barcode Box Storage Berbasis Digital Literacy Acceleration Skills In The Knowledge Age “
Penelitian ini bertujuan untuk : (1) Mendeskripsikan proses pengembangan media (B3-S) Bright Barcode Box Storage Berbasis Digital Literacy Acceleration Skills untuk meningkatkan kemampuan "The $4 C$ Skills" siswa SD kelas III pada mata pelajaran Tematik. (2) Mendekripsikan hasil pengembangan pengembangan media $(B 3-S)$ Bright Barcode Box Storage Berbasis Digital Literacy Acceleration Skills untuk meningkatkan keterampilan 4C collaboration skill, communication skill, critical thinking and problem solving skill, creativity and innovation skill pada era literacy acceleration in the knowledge age in the 21st Century Skills .

Adapun rencana didalam penelitian ini nantinya adalah adanya peningkatan ketrampilan 4C abad 21 yang meliputi Collaboration skill, Communication skill, Critical Thinking and Problem Solving skill, Creativity and Innovation skill Untuk itu peneliti melakukan pengembangan desain media yang inovatif yaitu "(B3-S) Bright Barcode Box Storage Berbasis Digital Literacy Acceleration Skills In The Knowledge Age "Media yang dapat meningkatkan kemampuan skill literasi digital sejalan dengan tuntutan pendidikan di Era Pembelajaran Abad 21 (The 21st Century Skills) pada siswa kelas III SD pada saat proses pembelajaran.

Adapun system Penggunaan media yang dikembangkan tersebut bersubstansi pada penguasaan keterampilan belajar Abad 21 dimana akan membekali siswa dengan pengalaman belajar yang kreatif inovatif dan menyenangkan dalam suasanan belajar melalui optimalisasi 4 jenis keterampilan sekaligus yaitu Communication, Collaboration, Critical Thinking and Problem Solving, Creativity and Innovation dimana dalam penggunaan media (B3-S) Bright Barcode Box Storage siswa diberikan 
kesempatan menggunakan kemampuannya untuk mengutarakan ide-ide dari siswa pada saat melakukan aktifitas literacy melalui problem solving melalui fitur tools berupa game board advance berteknologi barcode system, serta barcode flash card baik itu pada saat berdiskusi dengan teman-temannya maupun ketika siswa menyelesaikan soal yang berisi problem solving secara mandiri pada mata pelajaran tematik tersebut.

Hal itu bertujuan agar siswa memiliki kemampuan berpikir kritis melalui petunjukpetunjuk yang ada pada media (B3-S) Bright Barcode Box Storage Berbasis Digital Literacy Acceleration Skills In The Knowledge Age Sehingga nantinya media tersebut dapat menjawab tantangan pengembangan dunia pendidikan SD dalam memasuki Era age knowledge base The 21st Century Skills. hal ini pun sejalan dan sinergi pada pencapaian renstra UMSIDA yang telah dinyatakan dalam road map penelitian social humaniora LPPM Umsida yaitu pada point 8 tentang pengembangan inovasi pendidikan dan budaya Literasi.

Berdasarkan uraian diatas diperlukan pengembangan suatu media inofative yang dapat digunakan siswa belajar sekaligus bermain, agar dapat meningkatkan ketrampilan 4C abad 21 yang meliputi Collaboration skill, Communication skill, Critical Thinking and Problem Solving skill, Creativity and Innovation skill . Oleh karena itu, peneliti tertarik untuk melakukan penelitian dengan judul : Pengembangan Media (B3-S) Bright Barcode Box Storage Berbasis Digital Literacy Acceleration Skills In The Knowledge Age Untuk Meningkatkan Keterampilan Belajar Abad 21 (The 21st Century Skills)

\section{Sasaran Penelitian}

Sasaran Objek penelitian pengembangan dalam penelitian ini adalah media (B3-S) Bright Barcode Box Storage
Berbasis Digital Literacy Acceleration Skills In The Knowledge Age. Dan sasaran subjek dalan penelitian pengembangan media ini adalah siswa kelas III SDN Kejaten I Sidoarjo.

\section{Lokasi Penelitian}

Lokasi penelitian adalah tempat dimana penelitian dilakukan, penelitian pengembangan media (B3-S) Bright Barcode Box Storage Berbasis Digital Literacy Acceleration Skills In The Knowledge Age. Adapun yang dijadikan tempat penelitian pengembangan ini adalah SDN Kejaten I Sidoarjo , serta yang dijadikan tempat untuk menerapkan fase-fase penelitian yaitu fase implementasi adalah SDN Kejaten I Sidoarjo.

\section{METODE PENELITIAN}

Pendekatan Penelitian ini menggunakan pendekatan penelitian dan pengembangan (Research and Development), dengan dilakukan penyederhanaan langkah, dari sepuluh langkah (Borg \& Gall, 2003 :571), menjadi tiga tahap, yaitu: studi pendahuluan, pengembangan, dan validasi. Selanjutnya peneliti mengadaptasi berdasarkan pada ketentuan dan kebutuhan dalam Pengembangan media "(B3-S) Bright Barcode Box Storage Berbasis Digital Literacy Acceleration Skills In The Knowledge Age “.

Adapun rencana didalam penelitian ini nantinya adalah adanya peningkatan ketrampilan 4C collaboration skill, communication skill, critical thinking and problem solving skill, creativity and innovation skill pada era literacy acceleration in the knowledge age in the 21st Century Skill siswa SD kelas III pada saat proses pembelajaran melalui penggunaan media “(B3-S) Bright Barcode Box Storage Berbasis Digital Literacy Acceleration Skills In The Knowledge Age ".yang dikembangkan 
melalui petunjuk yang ada pada media. Secara umum media (B3-S) Bright Barcode Box Storage Berbasis Digital Literacy Acceleration Skills In The Knowledge Age berbentuk box package dengan dilengkapi code barkode pada 3 jenis connect tools box nya, memiliki stage / partisi yang sudah dikodifikasi sesuai dengan Content kompetensi materi dan tema pada K-13, dimana tiap boks package barcode yang memiliki link barcode dan telah disusun sistematis sehingga sintak konsep materi start dari yang paling sederhana ke konsep yang kompleks.

Media ini juga memiliki beberapa tools seperti dadu yang berisi 6 buah barkode di sisi-sinya nya dengan fitur tambahan berupa game board advance berteknologi barcode system, flash card dengan integrasi soal berbacode, dan melalui tools tambahan wajib yaitu scaneer barcode tools atau Handphone android yang sudah terinstall Aplikasi QR Code (lalu camera berfungsi sebagai alat scanner barcode) yang kemudian meng connected kan link barcode masuk kepada URL kuis soal online dan media video interaktif yang menjadi komponen dari media , maka semua gambar icon barcode yang ada dalam paket media (B3-S) Bright Barcode Box Storage akan membawa siswa pada learning experience literasi berbasis digital (blanded learing) dan cara memainkan media ini mewajibkan adanya kolaborasi oleh 4 siswa atau lebih yang memiliki latar belakang ketertarikan pada bahan bacaan tema sains dan ipteks yang menjadi habits atau kebiasaan seseorang siswa tersebut

Maka inilah yang disebut dengan keterampilan belajar Abad 21 dimana mewajibkan mereka belajar dengan 4 jenis keterampilan sekaligus (Communication, Collaboration, Critical Thinking and Problem Solving, Creativity and Innovation) dimana siswa nantinya diharapkan mampu untuk menguasai skill keterampilan belajar Abad 21. Hal ini pun sejalan dan sinergi pada pencapaian renstra UMSIDA yang telah dinyatakan dalam road map penelitian social humaniora LPPM Umsida yaitu pada point 8 tentang pengembangan inovasi pendidikan dan budaya Literasi.

\section{Instrumen Penelitian dan Teknik Pengumpulan Data}

Instrumen penelitian merupakan suatu alat yang digunakan untuk mengukur fenomena sosial maupun venomena alam. Instrumen penelitian yang diperlukan ada empat jenis, yaitu (1) lembar validasi, (2) lembar observasi penggunaan media $(B 3-S)$ Bright Barcode Box Storage Berbasis Digital Literacy Acceleration Skills In The Knowledge Age, (3) lembar Tes Kemampuan Berpikir Kritis Siswa, dan (4) lembar respons siswa. Berikut dijelaskan secara rinci tahaptahap dalam penelitian pengembangan yang dilakukan dalam pengembangan instrument (Plomp, Khabibah, 2006 : 89) :

1. Lembar Validasi media (B3-S) Bright

Barcode Box Storage Berbasis Digital

Literacy Acceleration Skills In The

Knowledge Age,

Lembar validasi ini digunakan untuk memperoleh data tentang kevalidan media (B3-S) Bright Barcode Box Storage Berbasis Digital Literacy Acceleration Skills In The Knowledge Age oleh validator mengenai aspek-aspek dan rancangan media, selanjutnya penilaian validator tersebut dijadikan pedoman peneliti untuk merevisi rancangan media pengembangan.

2. Lembar Observasi Penggunaan media

(B3-S) Bright Barcode Box Storage

Berbasis Digital Literacy Acceleration

Skills In The Knowledge Age,

Lembar observasi digunakan untuk mengamati aktivitas siswa saat menggunakan media (B3-S) Bright Barcode Box Storage 
Berbasis Digital Literacy Acceleration Skills In The Knowledge Age. Aktivitas tersebut meliputi pembentukan kelompok, pembagian bagian media, pemilihan petunjuk-petunjuk sesuai bagian kelompoknya, bertanya, menjawab dan berdialog.

3. Tes Kemampuan Berpikir Kritisf Siswa (TKBK)

Tes Kemampuan Berpikir Kritis siswa ini dikembangkan berdasarkan komponen Memfokuskan,

Mempertimbangkan, Mendefinisikan, Memutuskan. Tes Kemampuan Berpikir Kritis ini dinilai berdasarkan indikator berpikir kritis menurut Norris dan Ennis (1994). Tes Ketrampilan Berpikir Kritis ini diberikan kepada siswa setelah siswa bermain serta menggunakan media (B3-S) Bright Barcode Box Storage Berbasis Digital Literacy Acceleration Skills In The Knowledge Age materi keorganisasian sekolah dan masyarakat.

4. Angket Respons Siswa

Angket respons yang dikembangkan yaitu angket respons siswa yang digunakan untuk mengumpulkan data tentang respons atau tanggapan siswa terhadap media (B3-S) Bright Barcode Box Storage Berbasis Digital Literacy Acceleration Skills In The Knowledge Age. Angket ini diberikan pada siswa setelah siswa melakukan aktivitas permainan menggunakan kartu domica dan menjawab TKBK. (Borg \& Gall, 2009 : 317)

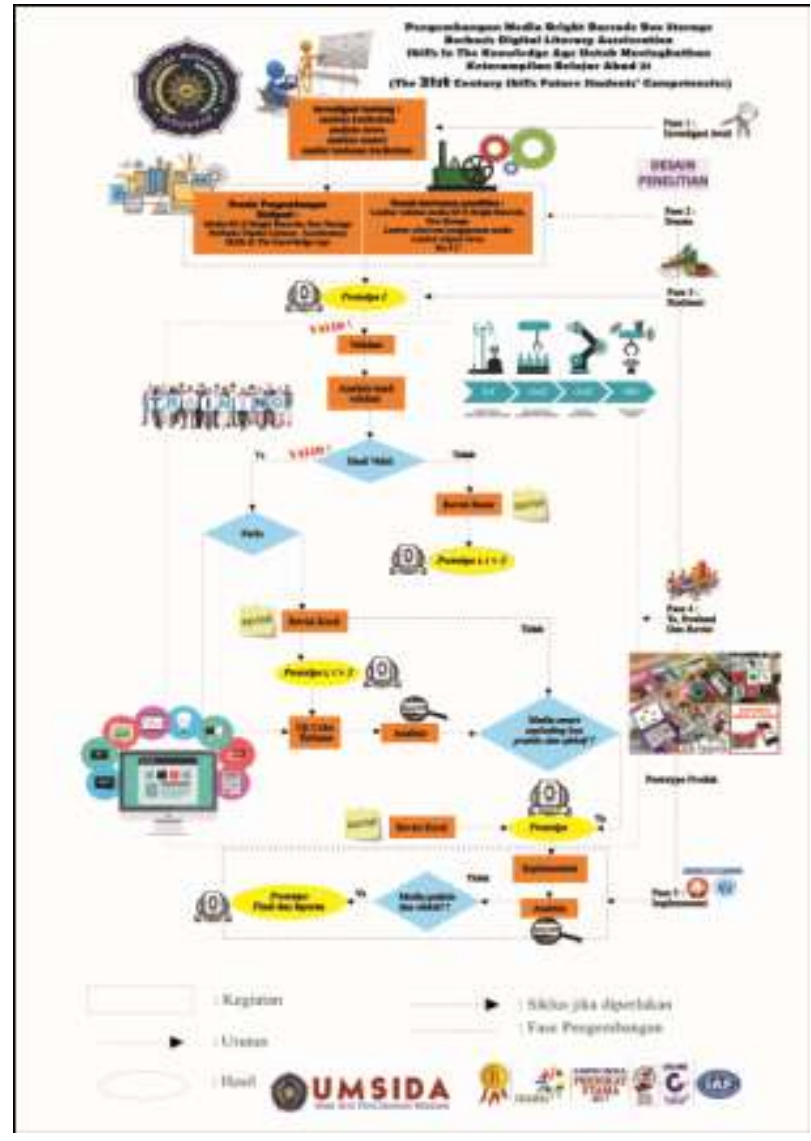

\section{HASIL DAN PEMBAHASAN Deskripsi Hasil Pengembangan Perangkat Pembelajaran}

Salah satu tujuan pelaksanaan penelitian ini sebagaimana dikemukakan pada BAB I adalah dihasilkannya sebuah Desain media (B3-S) Bright Barcode Box Storage Berbasis Digital Literacy Acceleration Skills In The Knowledge Age yang nantinya akan di internalisasikan pada mata pelajaran Tematik K-13 untuk mencapai tujuan tersebut, terlebih dahulu dilakukan pengembangan perangkat pembelajaran dengan mengadopsi dan menggunakan model pengembangan Dick dan Carey seperti telah diuraikan pada metodologi penelitian. Menurut (Djhiri, Dasim budimansyah dan supriya, $2013: 125$ ) dinyatakan bahwa efektifitas pembelajaran dimulai dari hasil kajian dari teori dan 
praktik pendekatan lalu di implementasikan dalam sebuah perangkat pembelajaran yang inovatif . Dalam penelitian ini telah dilakukan Uji Coba I, dan peneliti sendiri yang bertindak sebagai guru pengajar. Adapun perangkat pembelajaran yang dikembangkan dalam penelitian ini adalah; (1) Silabus dan Rencana Pelaksanaan Pembelajaran; (2) buku ajar media (B3-S) Bright Barcode Box Storage Berbasis Digital Literacy Acceleration Skills In The Knowledge Age (Buku Ajar dan LKS termasuk di dalamnya), dan; (3) Tes Hasil Belajar (THB). Pada penelitian ini telah dilaksanakan Uji Coba I di SD Kelas 3 semester 2, berikut ini akan disajikan deskripsi data hasil penelitian Uji Coba I.

\section{A. Rencana Pelaksanaan Pembelajaran (RPP)}

RPP merupakan suatu pedoman yang dirancang secara sistimatik berupa langkahlangkah kegiatan pelaksanaan pembelajaran yang digunakan guru dalam kegiatan belajar mengajar di kelas. Langkah-langkah pelaksanaan kegiatan pembelajaran dalam RPP ini dituliskan dalam bentuk skenario berupa kegiatan guru dan siswa melalui kegiatan pendahuluan, kegiatan inti, dan penutup, dengan menggunakan media (B3-S) Bright Barcode Box Storage Berbasis Digital Literacy Acceleration Skills In The Knowledge Age, sesuai dengan alokasi waktu yang ditetapkan untuk tiap pertemuan. Adapun komponen RPP dalam penelitian ini yakni meliputi , Capaian Pembelajaran, Tujuan Instruksional Umum dan Khusus, indikator, tujuan pembelajaran, pengelolaan pembelajaran, sumber pembelajaran, alat dan bahan, kegiatan belajar mengajar dan penilaian. Penyusunan RPP akan dapat maksimal dilakukan oleh guru , apabila kita mengetahui dan memahami secara komperehensif mengenai standart penyusunan meliputi standart isi dan standart proses serta memahami base kurikulum dengan baik (Asri Budiningsih , 2010 : 98)

RPP yang dikembangkan dalam penelitian ini dirancang untuk dua kali pertemuan. Pada pertemuan pertama digunakan pada pelaksanaan pembelajaran untuk sub pokok bahasan memahami Peranan warga negara dalam berpartisipasi terhadap pembangunan Nasional di indonesia.

\section{B. Media Exploding Box berbasis Deep} Dialogue Critical Thinking untuk meningkatkan kemampuan berpikir kritis

Media ini adalah seperangkat Draft Desain dan Produk Media Pembelajaran Kreatif dengan media (B3-S) Bright Barcode Box Storage Berbasis Digital Literacy Acceleration Skills In The Knowledge Age pada mata pelajaran Tematik K-13 berserta perangkat pembelajarannya untuk meningkatkan kemampuan berpikir kritis siswa sejalan dengan tuntutan pendidikan di era revolusi industry 4.0. Dimana pengembangan media ini akan dilakukan sampai tahap desain / uji coba dengan sebuah hipotesis bahwa pengembangan media ini berpengaruh dalam meningkatkan kemampuan berpikir kritis siswa SD di kelas III SDN Ketajen I.

Guru yang kreatif dalam menyusun konten pembelajaran inovatif adalah guru masa depan yang dapat memberikan pengaruh terhadap target capaian pembelajaran yang sudah di standarisasikan (Geralach \& Ely, 1998 : 174) . Prototipe produk yang dihasilkan yaitu sebuah media (B3-S) Bright Barcode Box Storage Berbasis Digital Literacy Acceleration Skills In The Knowledge Age yang telah disusun satu paket dengan Modul , RPP dan silabusnya serta manual guide-nya dimana media ini memiliki berbagai jenis permainan games fun learning yang mampu menarik motifasi siswa agar mampu berdialog dan berinteraksi dengan sesama temannya dalam proses pembelajaran dalam pemikiran yang berlangsung kritis. Pendekatan Penelitian ini menggunakan pendekatan penelitian dan pengembangan 
(Research and Development), dengan dilakukan penyederhanaan langkah, dari sepuluh langkah (Jackson, Philip W. 1991:571), menjadi tiga tahap, yaitu: studi pendahuluan, pengembangan, dan validasi. Selanjutnya peneliti mengadaptasi berdasarkan pada ketentuan dan kebutuhan dalam Pengembangan media (B3-S) Bright Barcode Box Storage Berbasis Digital Literacy Acceleration Skills In The Knowledge Age.

Adapun rencana didalam penelitian ini nantinya adalah adanya peningkatan ketrampilan berpikir kritis siswa SD kelas III pada saat proses pembelajaran melalui penggunaan (B3-S) Bright Barcode Box Storage Berbasis Digital Literacy Acceleration Skills In The Knowledge Age yang dikembangkan melalui petunjuk yang ada pada media . Secara umum media (B3-S) Bright Barcode Box Storage Berbasis Digital Literacy Acceleration Skills In The Knowledge Age berbentuk box package dengan dilengkapi code barkode pada 3 jenis connect tools box nya , memiliki stage / partisi yang sudah dikodifikasi sesuai dengan content kompetensi materi dan tema pada $\mathrm{K}$ 13, dimana tiap boks package barcode yang memiliki link barcode dan telah disusun sistematis sehingga sintak konsep materi start dari yang paling sederhana ke konsep yang kompleks.

Media ini juga memiliki beberapa tools seperti dadu yang berisi 6 buah barcode di sisi-sinya nya dengan fitur tambahan berupa game board advance berteknologi barcode system, flash card dengan integrasi soal ber barcode, dan melalui tools tambahan wajib yaitu scaneer barcode tools atau handphone android yang sudah terinstall Aplikasi QR Code (lalu camera berfungsi sebagai alat scanner barcode) yang kemudian meng connected kan link barcode masuk kepada URL kuis soal online dan media video interaktif yang menjadi komponen dari media , maka semua gambar icon barcode yang ada dalam paket media (B3-S) Bright Barcode Box Storage akan membawa siswa pada learning experience literasi berbasis digital (blanded learing) dan cara memainkan media ini mewajibkan adanya kolaborasi oleh 4 siswa atau lebih yang memiliki latar belakang ketertarikan pada bahan bacaan tema sains dan ipteks yang menjadi habits atau kebiasaan seseorang siswa tsb, maka inilah yang disebut dengan keterampilan belajar Abad 21 dimana mewajibkan mereka belajar dengan 4 jenis keterampilan sekaligus (Communication, Collaboration, Critical Thinking and Problem Solving, Creativity and Innovation) dimana siswa nantinya diharapkan mampu untuk menguasi skill keterampilan belajar Abad 21 (Rohman, Muhammad. 2012 : 79).

\section{Tes Hasil Belajar (THB)}

THB merupakan alat yang digunakan untuk mengukur seberapa jauh pencapaian hasil belajar siswa terhadap tujuan pembelajaran yang telah dirumuskan. Tes yang telah dikembangkan berupa THB dan disusun dan dikembangkan bedasarkan tujuan pembelajaran dan indikator yang akan dicapai.

D. Deskripsi Hasil Validasi Perangkat Pembelajaran

Untuk mengetahui apakah perangkat pembelajaran yang telah dikembangkan sudah layak untuk digunakan, maka terlebih dahulu diberikan kepada pakar atau ahli untuk divalidasi. Adapun cakupan validasi oleh validator mencakup atau difokuskan pada tiga aspek yaitu isi, bahasa, dan format. Kelayakan perangkat pembelajaran ini divalidasi oleh 2 orang pakar, dilihat dari aspek validasi perangkat pembelajaran dan tingkat kesulitan Buku ajar.

Pelaksanaan validasi terhadap
perangkat pembelajaran yang telah
dikembangkan berupa RPP, Buku Ajar, dan
THB oleh pakar atau ahli dalam penelitian


berupa skor penilaian, koreksi dan saran. Hasil validasi berupa skor penilaian, koreksi dan saran inilah yang akan digunakan sebagai dasar untuk melakukan revisi dan penyempurnaan terhadap perangkat pembelajaran. Hasil revisi kemudian dikonsultasikan dan ditelaah oleh peneliti , untuk disempurnakan . Perangkat pembelajaran yang telah dikonsultasikan dan ditelaah oleh validator dan dinyatakan telah sesuai dengan koreksi dan saran validator kemudian disepakati bahwa perangkat pembelajaran valid serta layak digunakan.

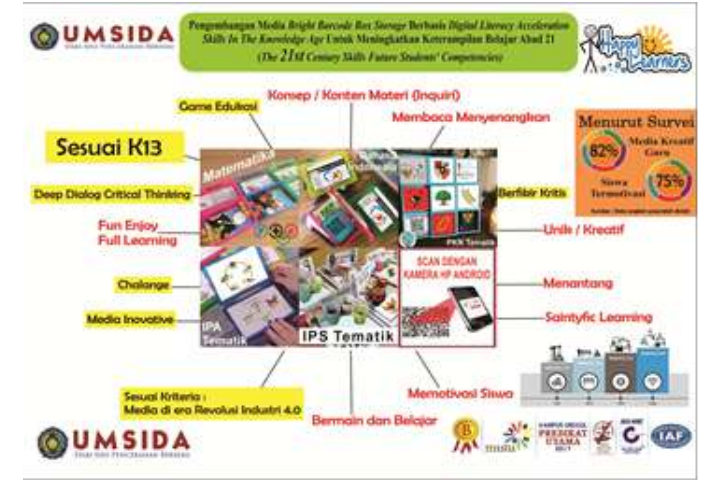

\section{E. Deskripsi Hasil Ujicoba Perangkat Pembelajaran}

Perangkat pembelajaran yang telah dikembangkan dan divalidasi oleh pakar atau ahli dan dinyatakan layak digunakan atau diterapkan sebagai perangkat pembelajaran dalam kegiatan belajar mengajar, selanjutnya diimplementasikan dalam kegiatan pembelajaran pada siswa SD Kelas III semester 2. Hal ini dimaksudkan untuk mengetahui efektifitas penerapan perangkat pembelajaran tersebut. Subjek penelitian Uji Coba I dan II adalah siswa SD Kelas III semester 2 sebanyak 32 siswa . Pada pelaksanaan Uji Coba I dan II dengan penerapan, peneliti bertindak sebagai guru untuk dua kali pertemuan, di luar pelaksanaan pre-test satu kali pertemuan, dan satu kali pertemuan untuk post-test hasilnya yang dicapai dari penelitian ini adalah adanya peningkatan kerampilan belajar siswa yang naik dengan menggunakan media interaktif digital sebesar $76 \%$ dalam hal kemampuan Communication, Collaboration, Critical Thinking and Problem Solving melalui (B3S) Bright Barcode Box Storage .

Data hasil penelitian dianalisis menggunakan statistik deskriptif yaitu dalam bentuk rata-rata, proporsi, nilai dan persentase. Berikut ini hasil analisis data dari Uji Coba I yang meliputi keterlaksanaan RPP, aktivitas siswa selama kegiatan belajar mengajar, respon siswa terhadap pembelajaran mata pelajaran Tematik K-13 dengan media media (B3-S) Bright Barcode Box Storage Berbasis Digital Literacy Acceleration Skills In The Knowledge Age

F. Aktivitas Siswa Dalam Pembelajaran Mata Pelajaran Tematik K-13 Dengan media (B3-S) Bright Barcode Box Storage Berbasis Digital Literacy Acceleration Skills In The Knowledge Age

Aktifitas pembelajarann Blanded Clasroom di Era Pembelajaran Digital adalah sebuah wujud perubahan konsep pembelajaran menuju kolaborasi pendidikan dan teknologi (Miles, M B dan Huberman, A. 2010 : 98) . Aktivitas siswa pada saat pelaksanaan kegiatan belajar mengajar berlangsung dengan penerapan media (B3-S) Bright Barcode Box Storage Berbasis Digital Literacy Acceleration Skills In The Knowledge Age. Dapat diamati atau dicatat oleh dua orang pengamat dengan menggunakan lembar pengamatan Instrumen 4. Data hasil analisis aktivitas siswa selama penerapan pembelajaran mata pelajaran Tematik K-13 dengan media (B3-S) Bright Barcode Box Storage Berbasis Digital Literacy Acceleration Skills In The Knowledge Age. menunjukkan bahwa siswa terlibat aktif dalam kegiatan pembelajaran pada Uji Coba I. Hal ini dapat dilihat dari persentase 
aktivitas siswa dalam mendengarkan/memperhatikan penjelasan guru adalah $14.81 \%$, membaca materi ajar adalah $12.5 \%$, mengerjakan LKS $14.6 \%$, dan berdiskusi dengan teman/siswa dalam kelompok dan guru 15.1 keempat aktivitas sangat menonjol dengan persentasenya cukup tinggi.

Dengan demikian dapat ditarik kesimpulan bahwa aktivitas yang dilakukan oleh siswa tersebut dapat dikategorikan sebagai aktivitas mengkonstruksi pengetahuan bagi dirinya sendiri atau dengan kata lain merupakan kegiatan pembelajaran berpusat pada siswa. Hasil pengamatan terhadap aktivitas siswa selama kegiatan belajar mengajar pada Uji Coba I dan II, yang dilakukan oleh dua orang pengamat dapat dipercaya dengan reliabilitas instrumen berkategori baik.

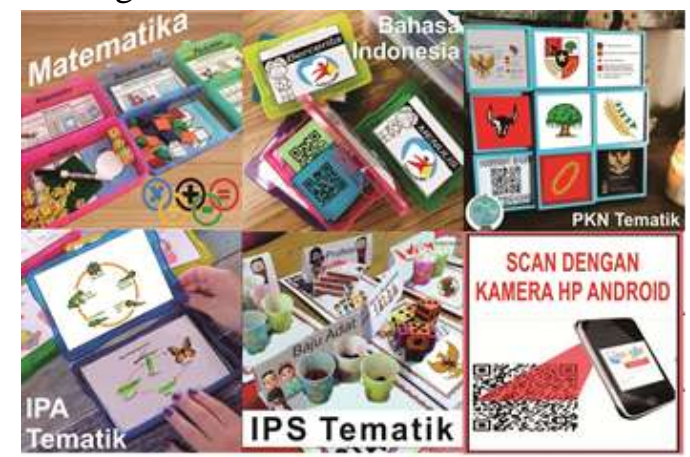

OUMSIDA
G. Respon Siswa Terhadap Kegiatan pembelajaran mata pelajaran Tematik K13 Dengan media (B3-S) Bright Barcode Box Storage Berbasis Digital Literacy Acceleration Skills In The Knowledge Age Pembinaan dan Pengembangan Kurikulum Berkarakter Literasi di Sekolah sangat penting dan utama sebab Literasi akan menghasilkan sebuah habituasi baik yang akan berpengaruh terhadap prestasi siswa , (Nana Sujana, 2005 : 67).

Untuk memperoleh data tentang bagaimana respon siswa setelah penerapan pembelajaran menunjukkan bahwa skor ratarata minat siswa terhadap penerapan pembelajaran mata pelajaran Tematik K-13 Dengan media (B3-S) Bright Barcode Box Storage Berbasis Digital Literacy Acceleration Skills In The Knowledge Age pada kegiatan Uji Coba I, diperoleh hasil yaitu tiga komponen dengan kategori baik yaitu, Attention (perhatian) skor rata-rata 4.31, Convidence (keyakinan) skor ratarata 4.12, dan Satisfaction (kepuasan) skor rata-rata 4.23, serta komponen Relevance (keterkaitan) dengan kategori sangat baik, dengan skor rata-rata 4.61. dan pada uji coba ke II Uji Coba I, diperoleh hasil yaitu tiga komponen dengan kategori baik yaitu, Attention (perhatian) skor rata-rata 4.65, Convidence (keyakinan) skor rata-rata 4.72, dan Satisfaction (kepuasan) skor rata-rata 4.7, serta komponen Relevance (keterkaitan) dengan kategori sangat baik, dengan skor rata-rata 4.7

\section{H. Hasil Belajar Siswa}

Hasil pembelajaran tematik sangat memiliki ciri khas khusus yang berbeda dengan kurikulum lainnya, yaitu memiliki sebuah skema kolaborasi terhadap jaring jarring tema antara mata pelajaran lainnya (Mastiono, 2016 : 98) . THB dalam penelitian ini ada dua yaitu THB Produk dan THB Proses. THB Produk digunakan untuk mengukur penguasaan siswa terhadap materi pelajaran yang telah diberikan untuk dua kali pertemuan pada pokok bahasan mengetahui keaneka ragaman sosial, budaya dan ekonomi dalam bingkai Bhinneka Tunggal Ika melalui pengamatan sesuai dengan tujuan 
pembelajaran yang telah dirumuskan. Ketuntasan tujuan pembelajaran dalam kegiatan belajar mengajar dengan menerapkan media (B3-S) Bright Barcode Box Storage Berbasis Digital Literacy Acceleration Skills In The Knowledge Age pada mata pelajaran Tematik K-13. Pada uji coba 1 dan uji coba II dapat dikatakan tuntas apabila proporsi semua tujuan pembelajaran besarnya (p) $\geq 0,70$. Sedangkan siswa dikatakan tuntas baik individu maupun klasikal jika proposi jawaban benar siswa (p) $\geq 0,70$.

Sehingga hasil yang dicapai dari penelitian ini adalah adanya peningkatan kerampilan belajar siswa yang naik dengan menggunakan media interaktif digital sebesar 76\% dalam hal kemampuan Communication, Collaboration, Critical Thinking and Problem Solving melalui (B3-S) Bright Barcode Box Storage ketuntasan tujuan pembelajaran setelah penerapan pembelajaran dengan strategi pembelajaran mata pelajaran Tematik K-13 dengan media (B3-S) Bright Barcode Box Storage Berbasis Digital Literacy Acceleration Skills In The Knowledge Age Hal ini dapat dibuktikan dari hasil analisis THB diperoleh data tentang proporsi tujuan pembelajaran berkisar antara 0.80 sampai 100 dengan rata-rata 0.95 , dengan demikian proporsi tujuan pembelajaran dikategori tuntas secara keseluruhan

\section{KESIMPULAN DAN SARAN}

\section{A. Kesimpulan}

Berdasarkan hasil uji coba ke-1 dan uji coba II yang telah dilaksanakan pada penelitian ini ditemukan sebuah data baru bahwa mata pelajaran Tematik K-13 pada kelas III SDN Ketajen Sidoarjo akan bisa berjalan lebih menarik jika para guru berminat untuk melakukan sebuah pengembangan dalam proses pembelajaran. Misalnya dengan menggunakan sistem pembelajaran mata pelajaran Tematik K-13 dengan media (B3-S) Bright Barcode Box Storage Berbasis Digital Literacy Acceleration Skills In The Knowledge Age. Sehingga hasil yang dicapai dari penelitian ini adalah adanya peningkatan kerampilan belajar siswa yang naik dengan menggunakan media interaktif digital sebesar 76\% dalam hal kemampuan Communication, Collaboration, Critical Thinking and Problem Solving melalui (B3-S) Bright Barcode Box Storage dan siswa memiliki ketertarikan dalam proses pembelajaran Tematik K-13 . dan pada saat pembelajaran Tematik K-13 tidak hanya mempelajari materi teori saja, tapi juga dapat berpikir kritis agar sejalan dengan Era Revolusi Industri 4.0.

Dengan adanya perumusan dan pengembangan media (B3-S) Bright Barcode Box Storage Berbasis Digital Literacy Acceleration Skills In The Knowledge Age untuk meningkatkan kemampuan berpikir kritis menghadapi era revolusi industri 4.0 pada mata pelajaran Tematik K-13 di kelas III SDN Ketajen Sidoarjo diharapkan bisa menjadikan nilai positif dan menjadikan sebuah nilai plus atau nilai tambah bagi kualitas output lulusan SDN Ketajen 1 Sidoarjo , sebab siswa yang lulus nantinya tidak hanya terbekali dengan kemampuan akademis dan pedagogis saja, namun juga dibekali oleh sebuah life skill yang berupa kemampuan berpikir kritis yang bermanfaat sebagai ilmu survive atau bekal hidup siswa nantinya agar bisa menciptakan ide peluang usaha industry kreatif dibidang pendidikan sesuai dengan background kepeminatan 
siswa nantinya. Kecerdasan emosional , kemampuan dalam 4C Skill adalah sebuah kewajiban yang harus dilakukan oleh setiap guru dalam menjawab era pembelajatan abad 21 (Setyawan Budi , 2017 : 56 ) Jurnal Online Lentera pendidikan

\section{A. Saran}

1. Melakukan Sebuah penelitian lanjutan atas data yang sudah didapatkan dengan scope mata pelajaran serumpun sehingga bisa dilakukan sebuah perbandingan hasil penelitian ini nantinya.

2. Melakukan sebuah pengayaan referensi baik dari sumber buku lokal maupun buku luar negeri serta jurnal penelitian dari dalam maupun luar negeri untuk memperkuat dasar riset selanjutnya.

3. Melakukan sebuah rekonstruksi media pembelajaran Tematik K-13 bagi siswa agar lebih up to date dalam menjawab perkembangan globalisasi dari segi perkembangan IPTEKS.

\section{REFERENSI}

Borg \& Gall..2009. Metode Penelitian Pendidikan Kuantitatif Kualitatif. New York: MacMilllan Publishing Company

C. Asri Budiningsih .2010. Pendekatan Deep Dialogue and Critical Thinking. Jakarta: Universitas Indonesia.

Cucu Suhana 2014. Guru Profesional: Untuk Pendidikan Bermutu. Bandung: Geografi Edu.

Djhiri, Dasim budimansyah dan supriya .2013. Kurikulum Berserta Model dan Pengajaran nya di SD, Jakarta: Bumi Aksara.

Frank Bobbit. 2017. Media Pendidikan dan Pengajaran Inovatif dalam Era Revolusi Industri 4.0. Terjemahan
Tjetjep Rohendi Rohisi. Jakarta: Universitas Indonesia.

Geralach \& Ely .1998. Mengangkat Citra dan Martabat Guru. Bandung : Adicita Karya Nusa.

Jackson, Philip W. 1991. Handbook of Research on Curriculum. New York : MacMilllan Publishing Company.

Jurnal Online Lentera pendidikan Setyawan Budi : 2017 dengan judul "Kemampuan Berfikir Kritis Siswa Sekolah Dasar Di Era Distrubsi Budaya Dan Gadget", Volume II Tahun 2016.

Mastiono.2016. Tematik di SD tantangan dan inovasi di era Multidimensi. Surakarta: Fairuz Media.

Miles, M B dan Huberman, A. 2010. Blanded Clasroom di Era Pembelajaran Digital. Terjemahan Tjetjep Rohendi Rohisi. Jakarta: Universitas Indonesia.

Miles, M B dan Huberman, A. 2010. Kemampuan Berfikir Kritis Pada Anak Usia Sekolah Dasar. Terjemahan Tjetjep Rohendi Rohisi. Jakarta: Universitas Indonesia.

Mulyasa. 2014. Kurikulum 13: Konsep, Karakteristik dan Implementasi, Bandung:PT. Remaja Rosdakarya.

Nana Sujana, 2005, Pembinaan dan Pengembangan Kurikulum Berkarakter Literasi di Sekolah, Jakarta : Sinar Baru Algensindo.

Norris and Ennis ,2007. Inovation Curriculum: Reading for Developing Quality Educational Programs. (Ninth Edition). Boston: Pearson.

Plomp, Khabibah, 2006 Metodologi Penelitian Kuantitatif. Bandung: PT. Remaja Rosda Karya .

Rohman, Muhammad. 2012. Kurikulum Berkarakter Berbasis Critical Thinking. Jakarta:Prestasi Pustakarya. 
WAHANA

Volume 72, Nomor 1, 1 Juni 2020

Suhardan, D. 2009. Manejemen Pendidikan.

Bandung: Alfabeta Sutama. 2010. 